CARVALHO, Rosane A. de. Produção audiovisual do artista goiano Paulo Fogaça. Domínios da Imagem, v. 12, n. 23, p. 6-17, jul./dez. 2018.

\title{
PRODUÇÃO AUDIOVISUAL DO ARTISTA GOIANO PAULO FOGAÇA
}

\section{AUDIOVISUAL PRODUCTION OF ARTIST GOIANO PAULO FOGAÇA}

\author{
Recebido em 29/9/2017 e aprovado em 30/1 1/2018
}

Rosane A. de Carvalho•

Resumo: Fotografia, vídeo, fotocópia, fax, computador e audiovisual - slides sincronizados a sons de fitas cassetes - foram alguns meios, pautados na imagem técnica, apropriados por alguns artistas brasileiros na década de 1970 no Brasil. Destaco neste artigo três audiovisuais produzidos pelo artista goiano Paulo Fogaça (1936 - ): Bichomorto, Hieróglifos e Campo Cerrado. O objetivo é apontar para o diálogo entre as imagens constituintes de tais audiovisuais com o momento artístico, imerso em pesquisas experimentais, tanto imagéticas como sonoras e, ainda com o político, que foi o da ditadura militar. Destaco a presença recorrente da imagem do arame farpado como elemento discursivo do contexto cerceador que pairava sobre a sociedade brasileira daquela época, tanto por suas qualidades físicas, como objetivas, ou seja, de uso.

Palavras-chaves: audiovisual. Experimentalismo. Ditadura militar.

Abstract: Photography, video, photocopy, fax, computer and audiovisual slides synchronized with the sounds of cassettes - were some media, based on the technical image, appropriated by some brazilian artists in the 1970s in Brazil. I highlight in this article three audiovisual works produced by the goiano artist Paulo Fogaça (1936 -): Bichomorto, Hieróglifos and Campo Cerrado. The objective is to point the dialogue between the constituent images of these audiovisuals with the artistic moment, immersed in experimental researches, both imagistic and sonorous, and also with the political, which was the military dictatorship. I emphasize the recurrent presence of the barbed wire image as a discursive element of the restrictive context that loomed over the Brazilian society of the time, both because of its physical and objective qualities, that is, of use.

Keywords: audio-visual. Experimentalism. Military dictatorship.

\footnotetext{
- Doutoranda do Programa de Pós-graduação em Arte e Cultura Visual da Faculdade de Artes Visuais/UFG. Orientadora: Prof.Dra. Rosana H. Monteiro.
} 
CARVALHO, Rosane A. de. Produção audiovisual do artista goiano Paulo Fogaça. Domínios da Imagem, v. 12, n. 23, p. 6-17, jul./dez. 2018.

ISSN 2237-9126

Nos anos 1970, o Brasil vivia sob o clima cerceador do governo ditatorial implantado desde a década anterior. Tal situação, no entanto não foi capaz de "castrar" a produção artística que já vinha expandindo seu campo de ação através de proposições centradas nas experimentações com novas tecnologias, bem como no embate com a situação política e social do país. Nesse contexto, podemos encontrar um conjunto de produção que tinham como base o uso das imagens técnicas, destaco neste artigo a produção audiovisual do artista goiano Paulo Fogaça' .

Ao me referir ao audiovisual, reporto-me ao sistema de projeção de slides, distribuídos no carretel do aparelho óptico-mecânico e sincronizados a sons (ruídos, narrações, diálogos, música etc.) gravados em fitas cassetes, que até aquele momento era utilizado tão-somente em meios educacionais, como veículo de divulgação e publicidade ou ainda em treinamento de profissionais.

A produção desses audiovisuais deveu-se muito ao esforço do críticocriador Frederico Morais que, como arregimentador e catalisador de proposições, sobretudo experimentais, demonstrou as potencialidades expressivas e discursivas do mesmo. Para Morais (1973 apud FERREIRA, 2006, p.392), o audiovisual é uma forma de arte e de expressão poética, enfim uma linguagem.

O audiovisual possui qualidades expressivas significativas que o difere do super-8, por exemplo, outro meio tecnológico que estava sendo experimentado por muitos artistas naquela época. A projeção do

\footnotetext{
1 Paulo Emílio Fogaça Neto nasceu na cidade de Morrinhos, em Goiás. Passou a sua infância entre a sua cidade natal e a capital do estado, Goiânia. Em 1952 mudou-se para a cidade do Rio de Janeiro, na época, Estado da Guanabara, onde concluiu o ginasial e ingressou na Escola Nacional de Engenharia na Universidade do Brasil (hoje Universidade Federal do Rio de Janeiro). Em 1962, retornou à Goiânia quando começou a trabalhar na Universidade Federal de Goiás. Com a implantação do governo militar, foi destituído de seu cargo de professor. Em seguida retornou ao Rio de Janeiro para trabalhar na estatal Eletrobrás. Esta segunda estada naquela cidade demarcou seu encontro definitivo com a produção artística por meio de cursos, coordenados por Frederico Morais, realizados no Museu de Arte Moderna. Após esse período, Fogaça viveu em Paris e no interior de Minas Gerais e atualmente vive na cidade de Goiânia, GO.
} 
CARVALHO, Rosane A. de. Produção audiovisual do artista goiano Paulo Fogaça. Domínios da Imagem, v. 12, n. 23, p. 6-17, jul./dez. 2018.

audiovisual é de caráter aberto, ou seja, apresenta possibilidades de conjugação com outros projetores, de alteração de foco, de posicionamento dos slides e tempo de exposição dos mesmos e, ainda, de expansão da imagem, que permite diferentes suportes para a projeção da mesma, o que não ocorre nos filmes de $16 \mathrm{~mm}$ e $35 \mathrm{~mm}$. Há ainda, o espaço negro entre uma imagem e outra que se soma ao ruído específico do projetor na transição dessas imagens - dos diapositivos.

Se o cinema é aparentemente mais livre na captação da realidade em movimento, na sala de projeção, ele se torna uma estrutura fechada. Pode-se dizer que a realidade do cinema está na câmara e a do áudio-visual no projetor. Ou seja, as infinitas possibilidades de combinações dos seus elementos materiais (slides, sons, focos de luz, retornos, zoons), entre si ou no momento da projeção. (MORAIS, 1973, p. 19).

Inicialmente, Morais utilizou o audiovisual como comentário crítico de trabalhos de artistas, como em "Memória da Paisagem", de 1971, que trata da exposição de Baravelli, Resende, Fajardo e Nasser realizadas no Rio de Janeiro. Posteriormente, inicia uma série de trabalhos autorais, alguns com a colaboração de Paulo Fogaça.

Paulo Fogaça trabalhou com Frederico Morais em alguns de seus audiovisuais realizando as fotografias para os mesmos, incluindo "Memória da Paisagem", já mencionado. Contudo, o que me interessa aqui é apresentar três audiovisuais de Fogaça - Bichomorto, Hieróglifos e Campo Cerrado - nos quais o artista dialoga tanto com o momento de experimentalismo com as novas linguagens, como com as questões prementes da vida social e política brasileira daqueles anos de repressão ditatorial. Para tanto, Fogaça toma imagens da paisagem e objetos oriundos, em especial do meio rural, como a imagem da farpa, elemento agressivo dado a sua funcionalidade, que tem presença determinante, sobretudo em Hieróglifos. 
CARVALHO, Rosane A. de. Produção audiovisual do artista goiano Paulo Fogaça. Domínios da Imagem, v. 12, n. 23, p. 6-17, jul./dez. 2018.

ISSN 2237-9126

Segundo André Parente:

A primeira característica do trabalho de Fogaça é a mistura de meios e a sua sobreposição. Ele não apenas emprega fotografia, desenhos, [...] como os sobrepõe. Os efeitos plásticos e sonoros resultantes criam uma espécie de imanência conceitual. Neste sentido, [...] em Fogaça, os audiovisuais se servem dos mesmos elementos plásticos utilizados em seus desenhos, pinturas, gravuras e objetos. (PARENTE, 2015, p.16).

As imagens constituintes do audiovisual Bichomorto (Figuras 01, 02 e 03) mesclam registros fotográficos de animais mortos às margens das rodovias, realizados durante uma viagem de férias, realizada com sua família, do Rio de Janeiro a Goiás, em 1973 com detalhes de mapas rodoviários. O artista justapõe essas imagens e ainda faz interferências gráficas sobre as mesmas. A sequência de 67 slides foi sincronizada aos registros de sons emitidos nas estradas e cidades - buzinas, freadas, o vento, vozes, carros transitando etc.

Dado o momento de repressão de liberdades e ideias, o assunto foi trabalhado em termos metafóricos. Assim, animais mortos por atropelamento nas rodovias podem ser associados às vidas interrompidas pela força e violência da ditadura militar. São corpos dilacerados pelos veículos que trafegam cotidianamente pelas rodovias. A violência é explicitada pelos corpos de animais esmagados, pelas marcas de pneus no asfalto e ainda pelas manchas gráficas avermelhadas colocadas sobre os corpos deixados à beira da estrada. Os mapas encobertos em tinta avermelhada que abrem o audiovisual reforçam a ideia de violência, esta espalhada pelo território nacional. É o artista delatando uma situação de repressão vivenciada pela sociedade brasileira diante dos atos violentos e cerceadores do regime ditatorial operante em todo território nacional. 
CARVALHO, Rosane A. de. Produção audiovisual do artista goiano Paulo Fogaça. Domínios da Imagem, v. 12, n. 23, p. 6-17, jul./dez. 2018.

ISSN 2237-9126

Vale trazer novamente o comentário de André Parente sobre Bichomorto:

[...] Outro aspecto geral de seu trabalho é a relação da paisagem natural com a paisagem mental. Em BICHOMORTO, não vemos apenas a violência das estradas e rodovias; as idas e vindas da polícia anunciam algo que se espraia pelo território nacional, que é menos do que o nosso território mental, de forma a trazer à tona a força física e a violência da polícia da ditadura - que incidia sobre nosso corpo porque fruto de seu poder de produção de subjetividade. (PARENTE, 2015, p.16).

Figura 01. Bichomorto. 1973Audiovisual. 67 diapositivos. 3minutos. Diapositivos n. 20

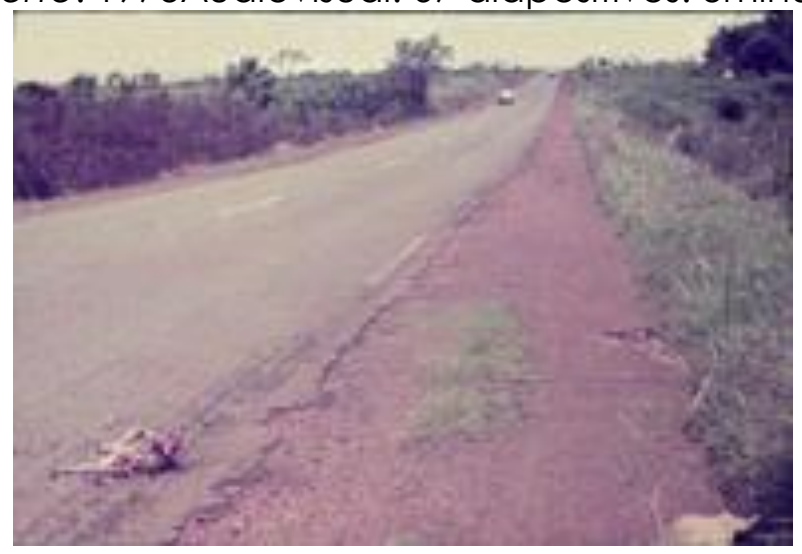

Foto: Paulo Fogaça

Figura 02. Bichomorto. 1973

Audiovisual. 67 diapositivos. 3minutos. Diapositivos n. 64

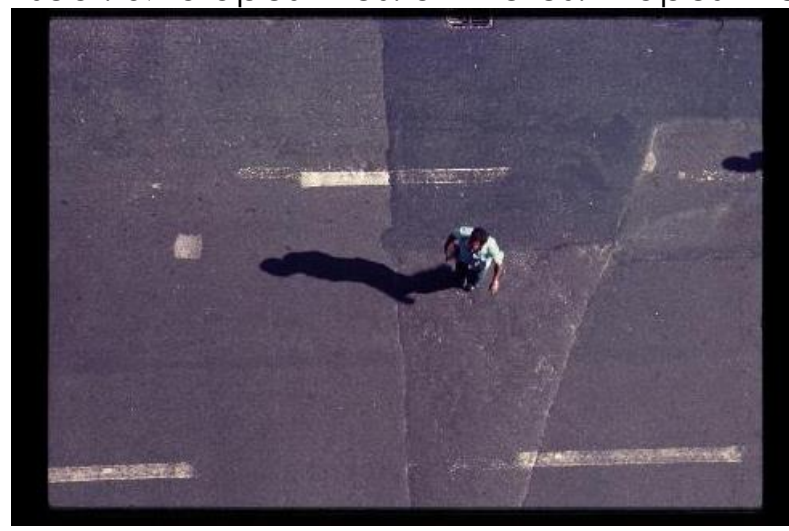

Foto: Paulo Fogaça 
CARVALHO, Rosane A. de. Produção audiovisual do artista goiano Paulo Fogaça. Domínios da Imagem, v. 12, n. 23, p. 6-17, jul./dez. 2018.

ISSN 2237-9126

Figura 03. Bichomorto. 1973

Audiovisual. 67 diapositivos. 3 minutos. Diapositivos n. 65

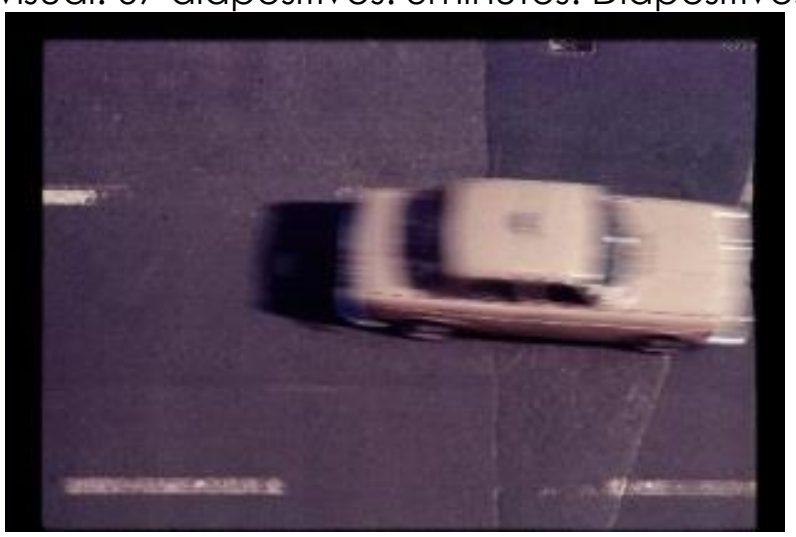

Foto: Paulo Fogaça

A sequência imagética apresenta a rodovia como lugar de trânsito e ligação de espaços geográficos onde estão os bichos mortos, enquanto no asfalto das grandes avenidas surge o homem solitário. A sequência final sugere o aniquilamento do homem pelo veículo que passa logo em seguida. Assim como o bicho, o homem também é dilacerado, num contexto no qual a violência se alastrou por todos os caminhos e direções; a fragilidade da vida é exposta diante de forças impositivas e autoritárias.

O engajamento nas questões de sua época, o olhar crítico sobre as injunções de seu tempo, que descrevia um momento delicado da história do Brasil, é revelado também no audiovisual Hieróglifos.

Nesse trabalho (Figuras 04, 05 e 06) o artista faz uso da metáfora para falar do cerceamento das liberdades e da violência através das qualidades intrínsecas do arame farpado, objeto agressivo, cortante, utilizado para impedir a passagem do gado dos limites de uma propriedade. Ao longo de sua produção, Fogaça utilizou o arame farpado ou sua imagem como veículo de comunicação do seu trabalho. A partir dele podemos fazer uma 
CARVALHO, Rosane A. de. Produção audiovisual do artista goiano Paulo Fogaça. Domínios da Imagem, v. 12, n. 23, p. 6-17, jul./dez. 2018.

série de associações, que vão desde a própria materialidade do objeto, chegando às implicações éticas e políticas que podem ser atribuídas à ele.

As imagens de Hieróglifos são manipuladas durante o seu processo de captação. A estrutura do elemento é exposta, por ora o objeto é quase diluído, tornando-se uma imagem abstrata, decorrente da exploração do processo técnico de captação da imagem. Em outros momentos partes do farpa são evidenciadas, também pela exploração dos recursos da fotografia em consonância com os propósitos discursivos do artista.

Figura 04. Hieróglifos. 1973.

Audiovisual. 77 diapositivos. 2' 20". Diapositivo n. 16.

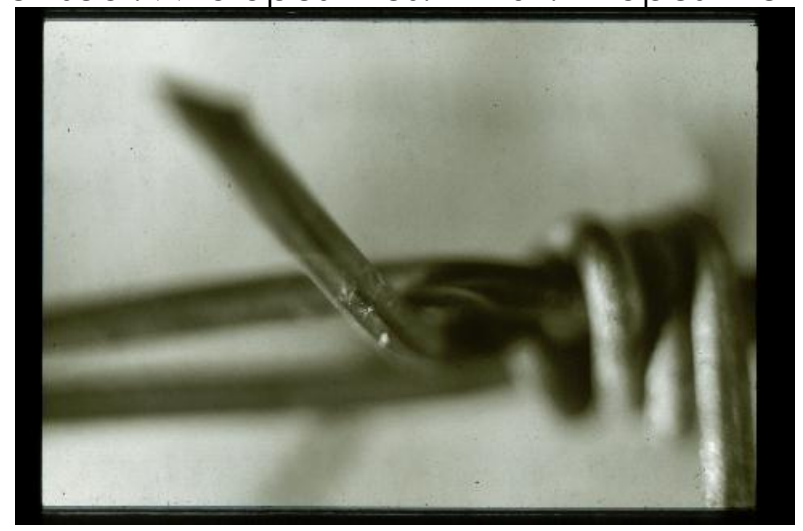

Foto: Paulo Fogaça

Figura 05. Hieróglifos. 1973.

Audiovisual. 77 diapositivos. 2' 20". Diapositivo n. 31.

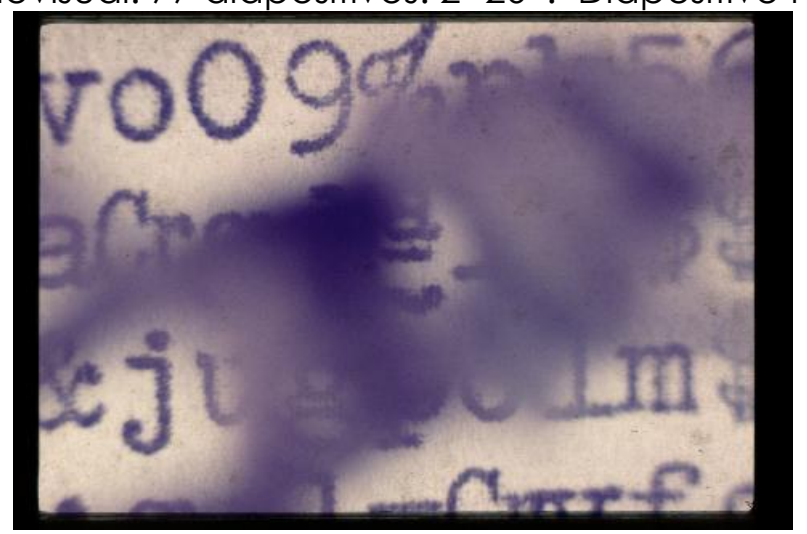

Foto: Paulo Fogaça

Neste trabalho, Fogaça também faz uso da justaposição de imagens. Corpos humanos surgem através de imagens de manuais de anatomia e são 
CARVALHO, Rosane A. de. Produção audiovisual do artista goiano Paulo Fogaça. Domínios da Imagem, v. 12, n. 23, p. 6-17, jul./dez. 2018.

ISSN 2237-9126

postos em diálogo com páginas de jornais da época e imagens da farpa em diferentes configurações. Há ainda, interferências gráficas sobre os mesmos, como em Bichomorto. O corpo que surge em meio às farpas, com suas referências anatômicas, podem ser associados aos inúmeros corpos que foram submetidos a tortura e aos desmandos arbitrários do poder militar. As imagens são acompanhadas pela fala do artista, que repete veemente a palavra "não", configurando numa espécie de recusa absoluta de algo ou de uma situação, que no caso era a negação dos atos coercitivos do governo ditatorial.

Para André Parente, Bichomorto e Hieróglifos:

[...] possuem um requinte visual, poético e experimentalista de rara beleza na produção do audiovisual. Ambos apontam para a questão do insuportável: viver sob um regime ditatorial, fascista, era análogo a ter um arame farpado amarrado ao corpo como um dispositivo de tortura. As estratégias de montagem das sequências de slides, as sobreposições das imagens, tudo leva a um sentimento de aniquilamento e de dilaceramento e ruptura do espaço, do corpo e da terra, deixando a sensação de que a violência da ditadura está em todo lugar. Mas este aspecto político da obra de Fogaça é tratado com grande apuro plástico-visual. (PARENTE, 2015, p.16).

Figura 06. Hieróglifos. 1973.

Audiovisual. 77 diapositivos. 2' 20". Diapositivo n. 44.

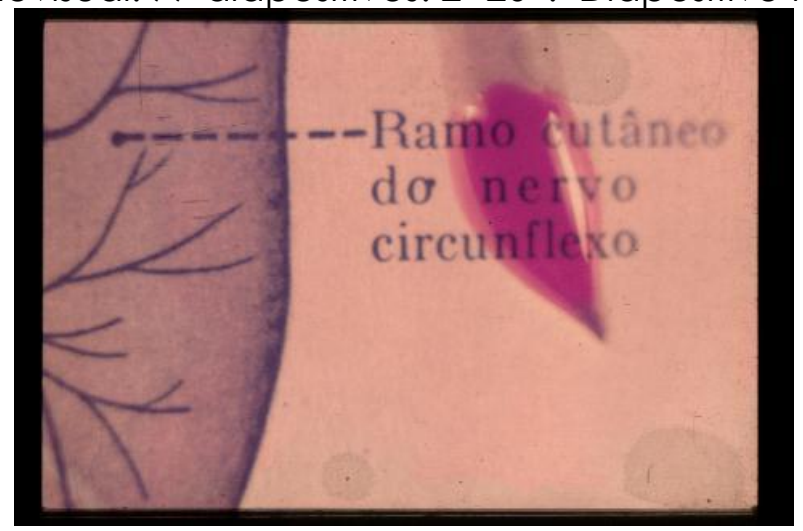

Foto: Paulo Fogaça 
CARVALHO, Rosane A. de. Produção audiovisual do artista goiano Paulo Fogaça. Domínios da Imagem, v. 12, n. 23, p. 6-17, jul./dez. 2018.

ISSN 2237-9126

Em Campo Cerrado (Figuras 07, 08 e 09), o foco recai sobre a paisagem do Cerrado. Há, nesse sentido, um pequeno desvio do tema da repressão política. Contudo, o discurso do artista ainda mantém vinculações com as questões sociais acrescido de uma preocupação ambiental de caráter delativo. Fogaça construiu uma narrativa visual a partir de registros do processo de transformação da paisagem do cerrado - o ciclo de vida e morte, o eterno renascer da vegetação.

Os primeiros diapositivos relatam a ação do homem sobre a vegetação do Cerrado - o resultado da queima da vegetação para servir de pasto para o gado. Posteriormente, o artista insere imagens que reafirmam a persistência da natureza em se refazer - surgem brotos e botões, flores e folhagens dançando ao som dos ventos. E a cerca, aquela de arame farpado, símbolo de restrição, volta à cena timidamente.

Figura 07. Campo Cerrado. 1975.

Audiovisual. 65 diapositivos. 8' 15". Diapositivos: 07

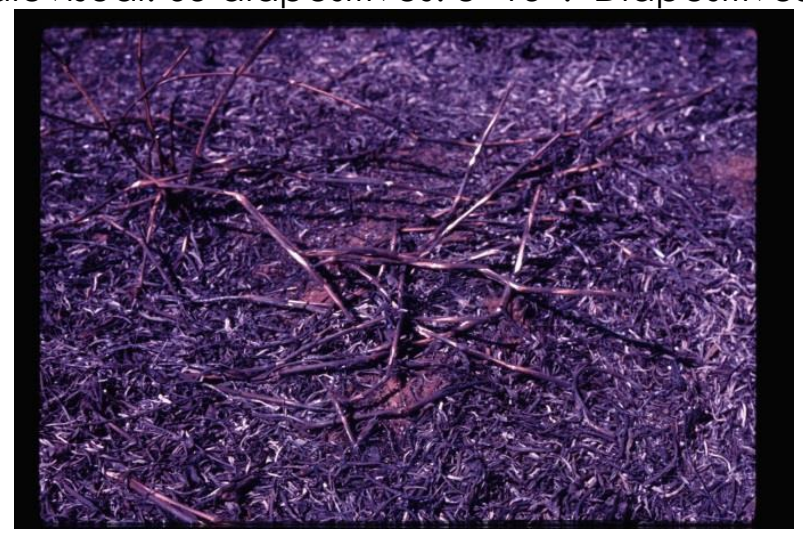

Foto: Paulo Fogaça

Figura 08. Campo Cerrado. 1975.

Audiovisual. 65 diapositivos. 8' 15". Diapositivos: 39 
CARVALHO, Rosane A. de. Produção audiovisual do artista goiano Paulo Fogaça. Domínios da Imagem, v. 12, n. 23, p. 6-17, jul./dez. 2018.

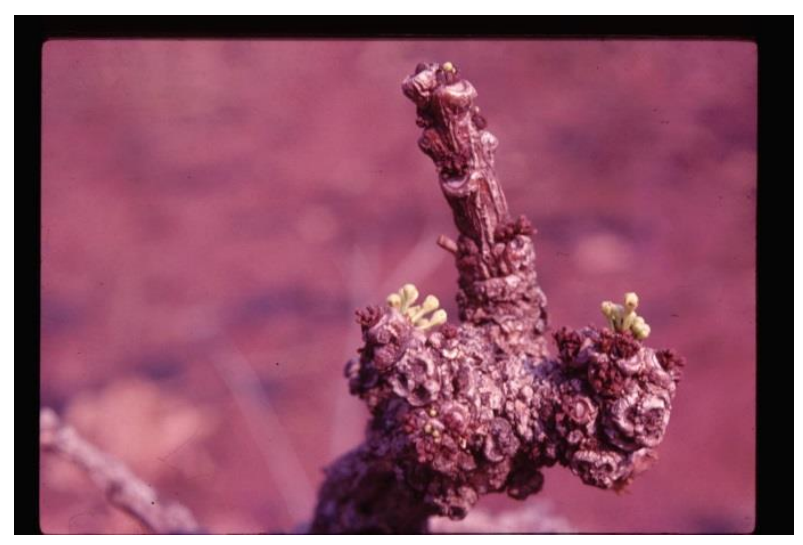

Foto: Paulo Fogaça

Figura 09. Campo Cerrado. 1975.

Audiovisual. 65 diapositivos. 8' 15". Diapositivos: 65

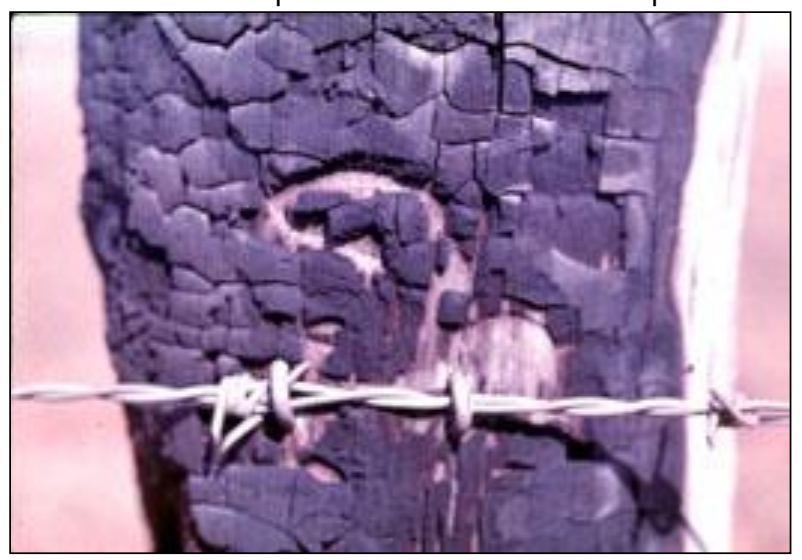

Foto: Paulo Fogaça

Nesse audiovisual, assim como em Bichomorto, Fogaça ocupou o lugar de testemunha para registrar os fatos que lhes são dignos de comentários. Apesar disso, os audiovisuais não se constituem em documentário para fins didáticos, ao contrário, a narrativa é pontuada de sentimento poético.

É importante assinalar que, Paulo Fogaça retornou o estado de Goiás e se instalou numa chácara próxima à capital, ambiente familiar e propício para tal pesquisa visual, após ter vivido por dez anos na cidade do Rio de Janeiro. Assim, é possível pensar que, esse retorno ao meio rural e sua 
CARVALHO, Rosane A. de. Produção audiovisual do artista goiano Paulo Fogaça. Domínios da Imagem, v. 12, n. 23, p. 6-17, jul./dez. 2018.

convivência com aquela paisagem desvelaram memórias de seu passado, inclusive de sua infância. Lembranças dos momentos de lazer vividos em seu ambiente de origem, onde foram germinadas e articuladas as relações afetivas e culturais que registram a sua identidade.

O cerrado faz parte da memória de minha infância: primeiro era o lugar para o qual, em qualquer época, os tios vez ou outra escapuliam para as casas das "raparigas"; depois, na época das chuvas, íamos apanhar os pequis maduros debaixo as árvores. A mente e os sentidos trabalhavam as sensações: o mistério de uma coisa, a visão do verde que rebrotava e o perfume dos pequis (FOGAÇA, 2009 apud CARVALHO, 2012, p.112).

Em Campo Cerrado, a literatura, assim como a canção de Caetano Veloso e Souzandrade ${ }^{2}$ acompanha a narrativa visual por meio de excertos de um texto do biólogo dinamarquês Eugênio Warming, de 1892, em que há uma descrição da paisagem do cerrado após a interferência humana - a queima da vegetação para servir de pasto para o gado, uma situação ainda presente nos tempos atuais. Para o artista a descrição do biólogo se assemelha a uma "poesia científica ou ciência poética"3. A convergência do pensamento de Fogaça com os escritos de Warming podem ser notados na designação que o artista deu aos seus audiovisuais; ele os intitulou de "diapoemas", propondo-os como "poemas visuais". Vale destacar que, essa denominação, "diapoemas", também foi dada aos dois audiovisuais aqui apresentados, Bichomorto e Hieróglifos. Essa atribuição dada pelo artista aos seus trabalhos reforça o caráter poético de seus trabalhos, a força expressiva das imagens que os constituem numa espécie de conjunção do meio (o audiovisual) com a carga semântica de suas imagens.

Após esse breve comentário sobre os audiovisuais Bichomorto, Hieróglifos e Campo Cerrado de Paulo Fogaça, é possível identificar a

\footnotetext{
2 "Gilberto misterioso" do disco gravado em 1970, Araçá Azul, é um poema de Sousândrade musicada por Caetano Veloso.

${ }^{3}$ Termo utilizado por Paulo Fogaça em entrevista concedida em 29 de agosto de 2005.
} 
CARVALHO, Rosane A. de. Produção audiovisual do artista goiano Paulo Fogaça. Domínios da Imagem, v. 12, n. 23, p. 6-17, jul./dez. 2018.

ISSN 2237-9126

conjunção do posicionamento engajado do artista nas questões de seu tempo com o interesse pelas experimentações da linguagem artística, em especial daquelas que exploraram o universo das imagens técnicas. A sua familiaridade com a paisagem rural, resgatada de suas lembranças e experiências quando ainda criança, foi determinante na escolha dessa visualidade para construir suas proposições. Contudo, o seu distanciamento daquele espaço, ou seja, do ambiente goiano, foi necessário para que o artista percebesse as potencialidades discursivas que aquela paisagem e seus elementos podiam conter. Esse distanciamento também foi imprescindível para que Fogaça se aproximasse e vivenciasse o ambiente cultural e artístico efervescente dos anos 1970, no Rio de Janeiro, que the permitiu realizar experimentações de processos tidos como inovadores, que em Goiás inexistiam naquela época. Assim, esses trabalhos, além de apontar para inserção do artista no universo experimental da produção artística dos anos 1970, nos leva a refletir sobre as questões relacionadas ao momento político do Brasil dos anos 1970, o estado coercitivo vivenciado pela sociedade brasileira, porém de forma poética e conceitual.

\section{Referências}

CARVALHO, Rosane A. Paulo Fogaça: o artista e seu tempo. Goiânia: Editora UFG, 2012.

MORAIS, Frederico. Audiovisuais. In: FERREIRA, Glória (Org.). Crítica de arte no Brasil: temáticas contemporâneas. Rio de Janeiro: FUNARTE, 2006. p. 391-394.

PARENTE, André; PARENTE, Lucas. Passagens entre fotografias e cinema na arte brasileira. Rio de Janeiro: +2 Editora, 2015.

\section{Catálogos de Exposições}

Exposição Áudio-visuais - Frederico Morais. Museu de Arte Moderna de São Paulo. 12 jun. a 23 jun. 1973. 
CARVALHO, Rosane A. de. Produção audiovisual do artista goiano Paulo Fogaça. Domínios da Imagem, v. 12, n. 23, p. 6-17, jul./dez. 2018.

Exposição Campo Cerrado. Museu de Arte e de Cultura Popular. Universidade Federal do Mato Grosso. 16 out.1979.

Exposição Expo-Projeção 73. Som, Audiovisual, Super 8, 16mm. São Paulo. Jun.1973. 